\title{
Pesticides Exposure: The Case of Workers on Growing Grapes in San Francisco Valley, Petrolina/Brazil
}

\author{
Francisco Alves Pinheiro', Paulo José Adissi² \\ ${ }^{1}$ Department of Production Engineering, Federal University of San Francisco Valley, Juazeiro, Brazil \\ ${ }^{2}$ Department of Production Engineering, Federal University of Paraiba, João Pessoa, Brazil \\ Email: francisco alvesp@yahoo.com.br, paulodissi@gmail.com
}

Received 27 May 2014; revised 29 June 2014; accepted 30 July 2014

Copyright (C) 2014 by authors and Scientific Research Publishing Inc.

This work is licensed under the Creative Commons Attribution International License (CC BY). http://creativecommons.org/licenses/by/4.0/

c) (i) Open Access

\begin{abstract}
The objective of this work is to analyze the systems of application of pesticides used in harvesting grapes of the sub-medium San Francisco valley, in relation to the risks of occupational contamination. The manual, mechanized and semi mechanized systems of application, adopted by the grape growers of the city of Petrolina/PE, have been analyzed through a method of both quantitative and qualitative evaluation. In such a way, two production units were visited: a mid-sized company and another one from of the CODEVASF. Five simulations were carried out in four systems of pesticide application using the European entire body method. Pre-application processes, such as storage and dilution of pesticides, as well as post-application processes, including equipment maintenance, cleaning and storage of clothes used for the application process were also analyzed. The results show large differences in risk among the systems that were analyzed and better conditions offered by the agricultural company, which was seeking to obtain the certification process.
\end{abstract}

\section{Keywords}

Agricultural Work, Growing Grapes, Chemical Risk, Pesticides Exposure

\section{Introduction}

On the banks of the San Francisco River, in the northeastern Brazilian territory, the cities of Petrolina/PE and Juazeiro/BA became centers for growth and development during the 1960s. This was largely due to investments in irrigation, which currently supplies 80,000 ha of government subsidized land and 60,000 ha of privately farmed land. The region is home to the country's largest individually owned vineyards, with a combined 5000 
ha planted and 18,000 direct jobs. The land area used for growing domestic grapes grew $71.8 \%$ from 2620 ha to approximately 4500 ha during 1991 to 1995 . This resulted in an overall production increase of 344\%, or 32,000 tons [1].

Because of the large growth and widespread irrigation system, growers have adopted new technological methods for vineyard maintenance, one of them being the conventional use of chemical substances for pest and disease control. The combination of these and other technologies and the richness of the San Francisco river region have vastly expanded the reach of agricultural development. This has created new challenges for the growers, especially regarding crop damage resulting from pest proliferation and favorable disease conditions that have already caused significant losses when preventive measures are not used.

\section{Methods for Measuring Dermal Exposure}

Several methods have been developed to assess exposure to pesticides and comprehensive reviews are available [2]-[6].

According to Organisation for Economic Co-Operation and Development (OECD) [7], the methods for measuring dermal exposure are classified in:

a Patch method-The patch dosimeter acts as a barrier to entrap pesticide that would impact on the clothing or, if the patch is located beneath the clothing, would otherwise reach the skin. Therefore, the composition of the patch and its location on each body region should be considered based on the type of pesticide formulation handled, the application equipment used, and the crop.

b Standard whole body dosimeter method-The whole body dosimeter acts as a barrier to entrap pesticide that would otherwise contact the clothing or, in the case of an inner dosimeter, would penetrate through the clothing to the skin. The dosimeter should cover the body, including the arms and legs to the wrists and ankles, and should fit well enough to avoid interference with hand washing or other activities. It should be constructed of suitable absorbent materials, such as cotton or cotton/polyester undergarments, socks, trousers, long-sleeved shirts and coveralls. Garments made of non-absorbent materials may be unsuitable for certain types of formulation.

c Variant of whole body (normal clothing) - A variant of the whole body method is the normal clothing approach. This approach involves the use of clothing and underwear that represents what the workers would normally wear, as outer and inner dermal dosimeters.

d The fluorescent tracer/video imaging method-This method involves the incorporation of a fluorescent tracer in a pesticide formulation and subsequent visual and quantitative analysis using a video imaging method. This method reveals non-uniform patterns of exposure that escape detection by the patch method.

The OECD [7] lists the main advantages and limitations of the above methods for estimating dermal exposure (Table 1).

Heavy usage of pesticides and herbicides is common and increasing in the Brazilian fruit culture. There are two growing seasons per year and chemicals are usually applied 6 to 8 times per growing season. It is known that the toxicants used are harmful and can affect many different groups related to the vineyards: workers, neighbors, visitors, product consumers, and fishermen and others who rely on exposed water sources [8].

Table 1. Main advantages and limitations of the methods for estimating dermal exposure.

\begin{tabular}{clc}
\hline Dermal Exposure Method & \multicolumn{1}{c}{ Main Advantages } & Main Limitations \\
\hline Patch & -Ease of analysis & -Assumes uniform deposition \\
Whole body & -No body region size or surface area correction necessary & -Analysis may be more cumbersome \\
& -Less time-consuming in the field & -May be uncomfortable for operator \\
Variant of & -Collects most pesticide not reaching skin & -Analysis may be more cumbersome \\
whole body & -No extrapolation required for body surface area & \\
& -Less time-consuming in the field & -Assumes equivalent clothing \\
Dyes/video & -Visual and quantitative analysis (conventionally or video imaging) \\
imaging & -Measures exposure directly from skin (video imaging) & permeation by dye and pesticide \\
\hline
\end{tabular}

Source: Adapted from OECD ([7], p. 17). 
According to Machera et al. [9], exposure to pesticides in farmers while using backpack sprayers mainly occurs through the dermal route represented more $99.0 \%$ of the total exposure among farmers applying pesticides with backpack sprayers. Thus, while studying exposure to pesticides in farmers using backpack sprayers, should aim to understand factors determining the level of exposure through dermal route.

In view of this reality, was evaluated the levels of exposure the pesticide appliers, by whole body methods, in the various methods of the spraying used in the Sao Francisco valley.

\section{Materials and Methods}

Two vineyard profiles were selected when determining units of study, taking into account levels of productivity.

- a medium-sized agricultural company that specialized in the growing of fresh fruits for export;

- local settler's farm, member of the Senator Nilo Coelho Irrigation Project, next to the San Francisco and Parnaiba Valley Development Corporation-CODEVASF.

Two different application systems used by the medium-sized company and three employees were chosen for exposure quantification tests. The first system involved an employee wearing backpack sprayer (model JACTO$20 \mathrm{~L}$ ) with wands $50 \mathrm{~cm}$ in length using a type JA2 nozzle. The toxicant application was high-volume, covering the vines until it dripped from the leaves.

The second system involved a tractor-mounted electric system using a turbo-atomizer with a capacity of 400 L, model JACTO-ARBUS 400 L (Figure 1).

The local settler used two other application systems. Each one was tested for level of exposure with the cooperation of two of the settler's workers. The third system involved a worker equipped with a 50-cm-wide paint roller and an open $5 \mathrm{l}$ bucket with a handle. The roller is used to apply the cianamide hydrogen (Dormex) to the vine's stumps resulting from trimming (Figure 2).

The fourth system, known as Capeta, involved an air-pressure sprayer driven by a $1 \mathrm{Hp}$ diesel engine and the same pump used by the ARBUS 400 L with a 200 L capacity (Figure 3). The contraption has pressure measurement and control devices and connections for two wands. The types of wands can vary depending on the product used and the purpose of the treatment. The entire contraption is mounted on an animal-powered wagon. One worker steers the animal and positions himself at a distance from the second worker who is manning the spray pistol, which is connected to the pump by a hose, and spraying the tops of the vines.

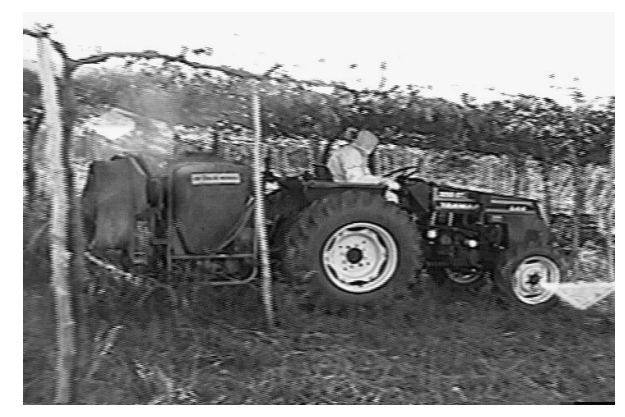

Figure 1. Simulation with turbo-atomizer.

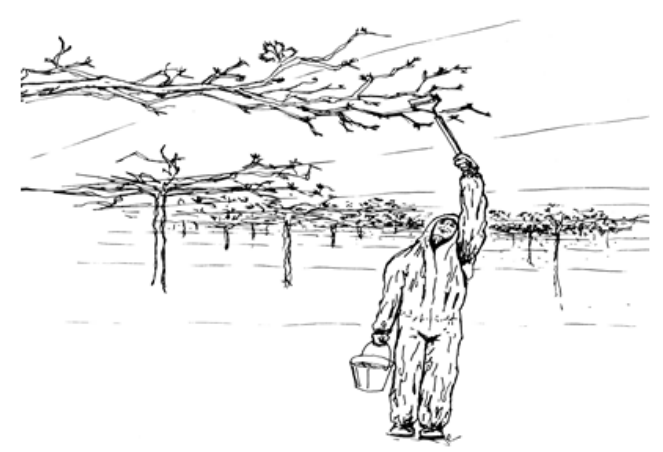

Figure 2. Simulation with paint roller. 


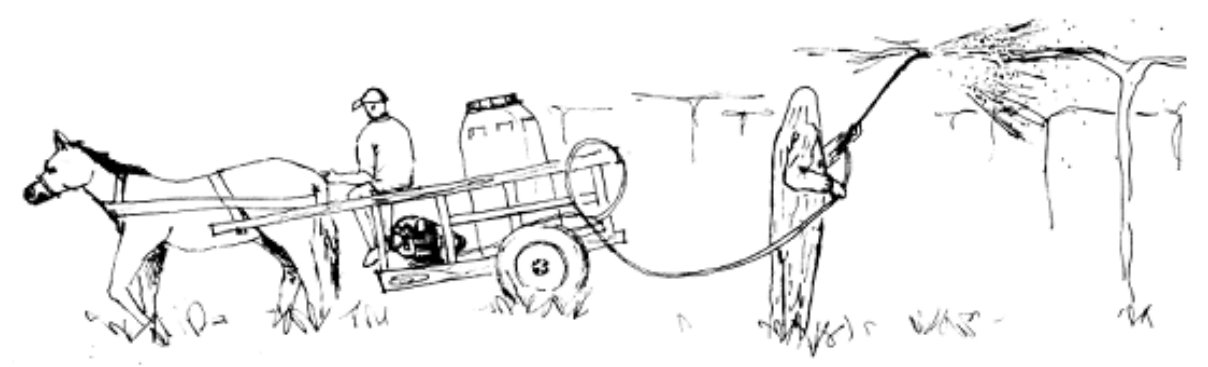

Figure 3. Simulation with equipment Capeta (side view).

In order to maintain the fidelity of the test simulations, the test subjects must be workers who are familiar with the handling of the toxicants and able to perform the necessary routine tasks. The simulations differed from a real scenario in two ways: the toxicants were replaced with "artificial coloring" and the worker's protective clothing was replaced with an especially absorbent suit that included a hood and gloves. After the dusting, the suit is cut into standard parts (Figure 4) using the European method developed by the United Kingdom's Ministry of Agriculture, Food, and Fishing's Central Science Laboratory for laboratory analysis [10]. Extraction of the coloring was done with a $10 \%$ acetone solution and the concentration of the mock-pesticide was performed using a spectrophotometer. The Spectrometer used was a Perkin Elmer LS 50-B at an excitation wavelength of 660 $\mathrm{nm}$ and integration's time of $1.0 \mathrm{~s}$.

The decision to use the same standards as those of the European Community was due mainly to the fact the European markets are the main target of the grapes from the Sao Francisco valley. A secondary motivation was the level of precision possible when using this method since it takes into accounts the whole body, rendering extrapolations needed by other methods dependent on localized droplet collectors unnecessary. In this way, the contamination risk can be evaluated based on the toxicity of the product and the level of exposure the worker faces [11] (Figure 4).

Toxicology can determine various parameters indicative of the toxicity of the products. For measuring the risk of chronic contamination occurrence, we used the non-observable effect level (NOEL) and the ingestion daily allowance (IDA). These measure acceptable daily levels of exposure, dermal or oral, that do not result in serious illness for humans.

The quantitative analysis of contamination risks seeks to compare the quantity absorbed during exposure (QAE) and the human tolerance limits determined by toxicology. We use $\mathrm{DL}_{50}$ for cases of acute contamination and NOEL for chronic contamination. To determine the QAE, it is accepted that $10 \%$ of the exposed dermal (ED) surface area and $100 \%$ of the exposed respiratory (ER) surface area are absorbent. When direct estimation is not possible, ER can be considered to be 1\% of the ED. Therefore, QAE can be defined as 11\% of the ED and risks can be calculating as follows:

Acute contamination

$$
\% D T=\frac{0.11 \times E D \times F S}{D L 50 \times P}
$$

Chronic contamination

$$
M S=\frac{N O E L \times P}{0.11 \times E D \times F S}
$$

where, "\%DT" is a percentage for the total dose, " $P$ " is the body weight of the worker (it is common to use 70 $\mathrm{kg}$ as the average weight of an adult male, "FS" is the safety factor, and "MS" is the safety margin. The security factor is necessary as an adjustment to take into account that the results from toxicology are estimates based on results with non-human subjects. These adopted factors vary considerably between authors, which points to a weakness in this method when trying to reach absolute conclusions. Therefore, the merit of this study is to objectively compare the safety of distinct situations and not determine that a given situation is safe or unsafe. The values for FS used in our calculations were 10 for $\% D T$ and 100 for MS.

The criteria used to interpret the value of MS and to classify safe work conditions, as a function of MS, according to Machado Neto [11], was the following: 


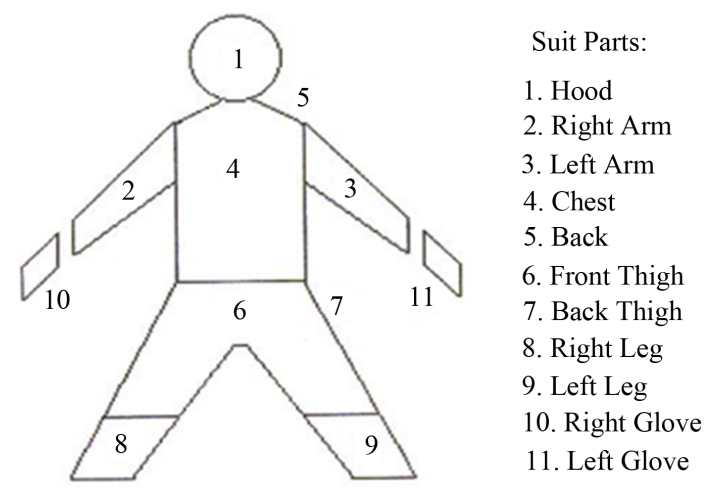

Figure 4. Cut the garment according to the body parts analyzed.

- If MS > 1, then the work condition is considered to be safe, that is, the level of exposure is tolerable and the risk acceptable, because the amount absorbed multiplied by the safety factor is less than the acceptable exposure (NOEL $\times 70 \mathrm{~kg}$ ), or the limit index value (LIV);

- If MS $<1$, then the work condition is considered unsafe, with the level of exposure and risk being unacceptable, because QAE $\times$ FS is larger than the acceptable exposure (NOEL $\times 70 \mathrm{~kg})$.

The determination of safe work time (SWT) and exposure control need (ECN) for unsafe work conditions (MS < 1) can also be used in management strategies dealing with pesticides risks. The calculation of SWT can be used as a safety measure to control occupational exposure in pesticide use. The calculation of ECN permits the selection of a more appropriate safety measure, for each working condition [12].

\section{Results and Discussion}

The results of all the simulations are synthesized in Table 2, where it is observed that method with the highest exposure potential was that using the Capeta (S2) followed by the backpack sprayers (S1). Subsequently, the system turbo atomizer (S3) and, lastly and lower risk, the paint roller (S4). The areas of the body that were most affected by the Capeta method were those of the head, torso, and upper-body limbs.

The simulations involving pressurized equipment registered the best- and worst-case ED results. The simulation with the turbo-atomizer (S3) registered a ED of only $59.3 \mathrm{ml} /$ day, while the capeta method (S2) registered an exposure rate of $1913.67 \mathrm{ml} /$ day.

The areas of the body of the tractor driver that were most affected were the gloves and back. For the worker with capeta system, the most affected body areas were upper-body limbs, chest, back, and right hand.

By variance analysis (ANOVA) can be concluded that the 4 treatments caused significantly different exposures $(\mathrm{F}=14.176>$ Fcrit $=2.839)$.

A toxic product from each toxicological class was used during evaluation, spanning all varieties of targets (pests, diseases, growth controllers) (Table 3).

The backpack sprayers simulations performed at agricultural firm, resulted in significantly level of exposure (EDS $=389.03 \mathrm{ml} /$ day) creating working conditions determined to be insecure (MS $<1$ ) for applications with Equation GDA and Folicur 200CE and secure for use of, Amistar 500 WG, Dipel insecticide and Pro-Gibb hormone (Table 4).

The Capeta method was deemed unsafe (MS $<1$ ) for working with Amistar 500 WG, Equation GDA, Folicur $200 \mathrm{CE}$ and required a level of exposure control (ECN) above 90\%. The only product used with the Capeta that was within safety parameters was the Dipel insecticide.

In Table 5, the turbo-atomizer system is considered safer than the Capeta sprayer with an EDS of 107.27 $\mathrm{ml} / \mathrm{day}(5.6 \%$ of S3-Table 2).

The simulation using Dormex and the paint roller method (S4) could only be evaluated in terms of probability of acute intoxication since the Noel of the product could not be determined (Table 6). The area of the body that suffered the greatest exposure was the right hand (the worker was right-handed).

The conditions of storage of pesticides, preparation of operations and care of application equipment and protective observed in medium-sized agricultural company were higher than those of settler’s farm. 
Table 2. Potential dermal exposure of the five employees on different Suit Parts.

\begin{tabular}{rccccc}
\hline & Suit Parts & Backpack Sprayers (S1) & Capeta (S2) & Turbo-Atomizer (S3) & Paint Roll (S4) \\
\hline C1 & Hood & 7.92 & 120.86 & 5.55 & 4.96 \\
C2 & Right Arm & 46.85 & 273.13 & 4.55 & 13.34 \\
C3 & Left Arm & 8.79 & 229.20 & 5.39 & 4.1 \\
C4 & Chest & 8.79 & 470.80 & 5.15 & 13.26 \\
C5 & Back & 24.32 & 228.48 & 8.83 & 13.86 \\
C6 & Front Thigh & 3.27 & 93.40 & 6.48 & 7.75 \\
C7 & Back Thigh & 22.20 & 50.53 & 2.76 & 4.24 \\
C8 & Right Leg & 15.21 & 68.92 & 1.37 & 3.02 \\
C9 & Left Leg & 15.98 & 50.22 & 2.21 & 0.47 \\
C10 & Right Glove & 42.17 & 240.24 & 8.50 & 33.61 \\
C11 & Left Glove & 193.53 & 87.90 & 7.95 & 8.50 \\
& ED (ml/day) & $\mathbf{3 8 9 . 0 3}$ & $\mathbf{1 9 1 3 . 6 7}$ & $\mathbf{1 0 7 . 2 7}$ & $\mathbf{5 9 . 3 0}$ \\
\hline
\end{tabular}

Concentration of the "artificial coloring”: $1.28 \mathrm{~g} / \mathrm{l}$.

Table 3. Toxicological information of pesticides.

\begin{tabular}{cccccc}
\hline Trade Name & Concentration (g/l) & Dosage (g/l) & Class Toxicological & DL50 Dermal (mg/kg) & NOEL (mg/kg/day) \\
\hline AMISTAR 500 WG & 500 & 0.24 & IV & 5000 & 18.2 \\
DIPEL & 33.6 & 1 & IV & 5000 & 4000 \\
EQUATION GDA & 300 & 50 & III & 2000 & 10 \\
FOLICUR 200 CE & 200 & 0.6 & III & 5000 & 30 \\
DORMEX & 520 & 1 & II & 848 & $*$ \\
PRÓ-GIBB & 1.00 & 0.015 & III & 5000 & 1000 \\
\hline
\end{tabular}

*Unknown Value. Source: EPA [13] [14].

Table 4. Simulation involving manual spray (S1).

\begin{tabular}{cccccc}
\hline Trade Name & EDS (mg/dia) & Risk (\%DT/dia) & MS & ECN (\%) & SWT (h) \\
\hline AMISTAR 500 WG & 72.7 & 0.02 & 1.59 & 0.0 & $\mathrm{t}>7$ \\
DIPEL & 302.7 & 0.10 & 84.08 & 0.0 & $\mathrm{t}>7$ \\
EQUATION GDA & 181.6 & 0.14 & 0.35 & 65.0 & 2.45 \\
FOLICUR 200 CE & 302.7 & 0.10 & 0.63 & 36.9 & 4.41 \\
DORMEX & 15.13 & 28.05 & - & - & - \\
PRÓ-GIBB & 4.5 & 0.001 & 1401.3 & 0.0 & $\mathrm{t}>7$ \\
\hline
\end{tabular}

Table 5. Simulation with Capeta (S2) and turbo-atomizer (S3).

\begin{tabular}{|c|c|c|c|c|c|c|c|c|c|c|}
\hline \multirow{2}{*}{ Trade Name } & \multicolumn{2}{|c|}{ EDS (mg/day) } & \multicolumn{2}{|c|}{ Risk (\%DT/day) } & \multicolumn{2}{|c|}{ MS (SF: 100) } & \multicolumn{2}{|c|}{ ECN (\%) } & \multicolumn{2}{|c|}{ SWT (h) } \\
\hline & S3 & S4 & S3 & S4 & S3 & S4 & S3 & S4 & S3 & S4 \\
\hline AMISTAR 500 WG & 357.4 & 11.1 & 0.11 & 0.003 & 0.32 & 10.46 & 67.6 & 0.0 & 2.27 & $t>7$ \\
\hline DIPEL & 1489.2 & 46.1 & 0.47 & 0.01 & 17.09 & 551.59 & 0.0 & 0.0 & $\mathrm{t}>7$ & $\mathrm{t}>7$ \\
\hline EQUATION GDA & 893.5 & 27.7 & 0.70 & 0.02 & 0.07 & 2.30 & 92.9 & 0.0 & 0.50 & $t>7$ \\
\hline FOLICUR 200 CE & 1489.2 & 46.1 & 0.47 & 0.01 & 0.13 & 4.14 & 87.2 & 0.0 & 0.90 & $t>7$ \\
\hline
\end{tabular}


Table 6. Simulation with roller method (S4).

\begin{tabular}{ccc}
\hline Trade Name & ED (ml/day) & DT/day\% \\
\hline DORMEX & 4173.9 & 7.73 \\
\hline
\end{tabular}

The company, which was about to be audited for the GlobalGAP certificate was defined protocols for all procedures in the storage and handling of pesticides and had the place to bath applicators and place of washing equipment, with collection and treatment of contaminated water. Moreover, the observed reality of settler unit indicated different risk situations, such as: storage of pesticides within easy reach along with clothing and personal equipment, food and seeds, workers without personal protective equipment and without proper place for bathing, creation sheep in the vineyard contaminated.

\section{Conclusions}

The use of pesticides by workers in the San Francisco Valley, proved acceptable in some application systems, where appropriate, especially the application by tractor with spray atomizer JET turbo-400 L. A little operator exposure is probably, for the safety of application equipment that allows the operator to keep up at a safe distance from the spray. The other application system that proved to be risky was acceptable to use the foam roller to apply Hydrogen Cyanamide (Dormex), however, what is observed in daily practice is that the employee, in seeking greater labor income neglects his protection and ends up crashing the runoff product on the skin, causing serious burns, which did not occur in the simulation.

The application system that provided greater exposure to workers was the system called Capeta, where the ECN reached $96.7 \%$ for the fungicide equation GDA control hardly attainable by all PPE found in the market today. The system with manual backpack sprayer is a system demanding in terms of protection and training.

These analyses have limitations on the number of repetitions applied to the systems and the number of applicators observed, as well as the execution time of simulations. It is worth noting the importance of the qualitative aspects which confirmed the observed discrepancies between the situations analyzed.

Beyond these considerations, it should be noted, finally, that it is always rash to extrapolate laboratory data obtained from small animals to humans, and even among humans, because we have a lot of variability.

Regarding the disposal of empty pesticide containers, it would be beneficial to promote environmental education campaigns for farmers and rural workers seeking greater awareness for the proper disposal of empty containers, as well as greater oversight of government agencies on the subject.

\section{References}

[1] CODEVASF (2002) Programa de Fruticultura: Relatório de Fases Produtivas. http://www.codevasf.gov.br/fruticultura

[2] Fenske, R.A., Simcox, N.J., Camp, J.E. and Hines, C.J. (1999) Comparison of Three Methods for Assessment of Hand Exposure to Azinphos-Methyl (Guthion) during Apple Thinning. Applied Occupational and Environmental Hygiene, 14, 618-623.http://dx.doi.org/10.1080/104732299302422

[3] Van Hemmen, J.J. and Brouwer, D.H. (1995) Assessment of Dermal Exposure to Chemicals. Science of the Total Environment, 168, 131-141. http://dx.doi.org/10.1016/0048-9697(95)04617-A

[4] Chester, G., Dick, J., Loftus, N.J., Woollen, B.H. and Anema, B.H. (1990) The Effectiveness of Protective Gloves in Reducing Dermal Exposure to, and Absorption of, the Herbicide Fluazifop-p-Butyl by Mixer-Loader-Applicators Using Tractor Sprayers. Proceedings of the 7th International Congress of Pesticide Chemistry, Vol. III, IUPAC.

[5] Abbott, I.M., Bonsall, J.L., Chester, G., Hart, T.B. and Turnbull, G.J. (1987) Worker Exposure to a Herbicide Applied with Ground Sprayers in the United Kingdom. American Industrial Hygiene Association, 48, 167-175.

[6] Durham, W.F. and Wolfe, H.T. (1962) Measurement of the Exposure of Workers to Pesticides. Bulletin of the World Health Organization, 26, 75-91.

[7] OECD (1997) Guidance Document for the Conduct of Studies of Occupational Exposure to Pesticides during Agricultural Application. Series on Testing and Assessment, No. 9, OECD/GD, Paris.

[8] Adissi, P.J., Menezes Melo, L.C. and Resende, S.R. (2001) Análise da aplicação manual de agrotóxicos em fruticultura. $53^{\mathrm{a}}$ REUNIÃO ANUAL DA SBPC, UFBA, Salvador.

[9] Machera, K., et al. (2003) Determination of Potential Dermal and Inhalation Operator Exposure to Malathion in Greenhouses with the Whole Body Dosimetry Method. Annals of Occupational Hygiene, 47, 61-70.

http://dx.doi.org/10.1093/annhyg/mef097 
[10] Glass, R. (2000) Exposure of Agricultural Workers to Pesticides in Southern Europe. Proceedings of Seminário Internacional sobre uso de Agrotóxicos, João Pessoa, Brasil.

[11] Machado Neto, J.G. (1997) Estimativas do tempo de trabalho seguro e da necessidade de controle da exposição ocupacional dos aplicadores de agrotóxicos. Ph.D. Dissertation, FCAV/UNESP, Jaboticabal.

[12] Machado Neto, J.G. (2001) Determination of Safe Work Time and Exposure Control Need for Pesticide Applicators. Bulletin of Environmental and Toxicology, 67, 20-26. http://dx.doi.org/10.1007/s001280086

[13] US Environmental Protection Agency-EPA (2009) Azoxystrobin; Pesticide Tolerances for Emergency. EPA, Washington DC. http://www.epa.gov/pesticides/

[14] US Environmental Protection Agency-EPA (2010) Safety of Bacillus thuringiensis Proteins Used to Control Insect Pest in Agricultural Crops. http://www.epa.gov/pesticides/

\section{Notes}

\section{List of Abbreviations}

\%DT-Percentage for the Total Dose

CODEVASF-San Francisco and Parnaiba Valley Development Corporation

Dormex-Trade Name of Hydrogen Cyanamide

ECN-Exposure Control Need

EDS-Simulated Dermal Exposure

GlobalGAP-Non-Governmental Organization that Sets Voluntary Standards for the Certification of Agricultural Products around the Globe

IDA-Ingestion Daily Allowance

LIV_-Limit Index Value

NOEL-Non-Observable Effect Level

OECD—Organisation for Economic Co-Operation and Development

SF-Safety Factor

SM-Safety Margin

SWT_-Safe Work Time 
Scientific Research Publishing (SCIRP) is one of the largest Open Access journal publishers. It is currently publishing more than 200 open access, online, peer-reviewed journals covering a wide range of academic disciplines. SCIRP serves the worldwide academic communities and contributes to the progress and application of science with its publication.

Other selected journals from SCIRP are listed as below. Submit your manuscript to us via either submit@scirp.org or Online Submission Portal.
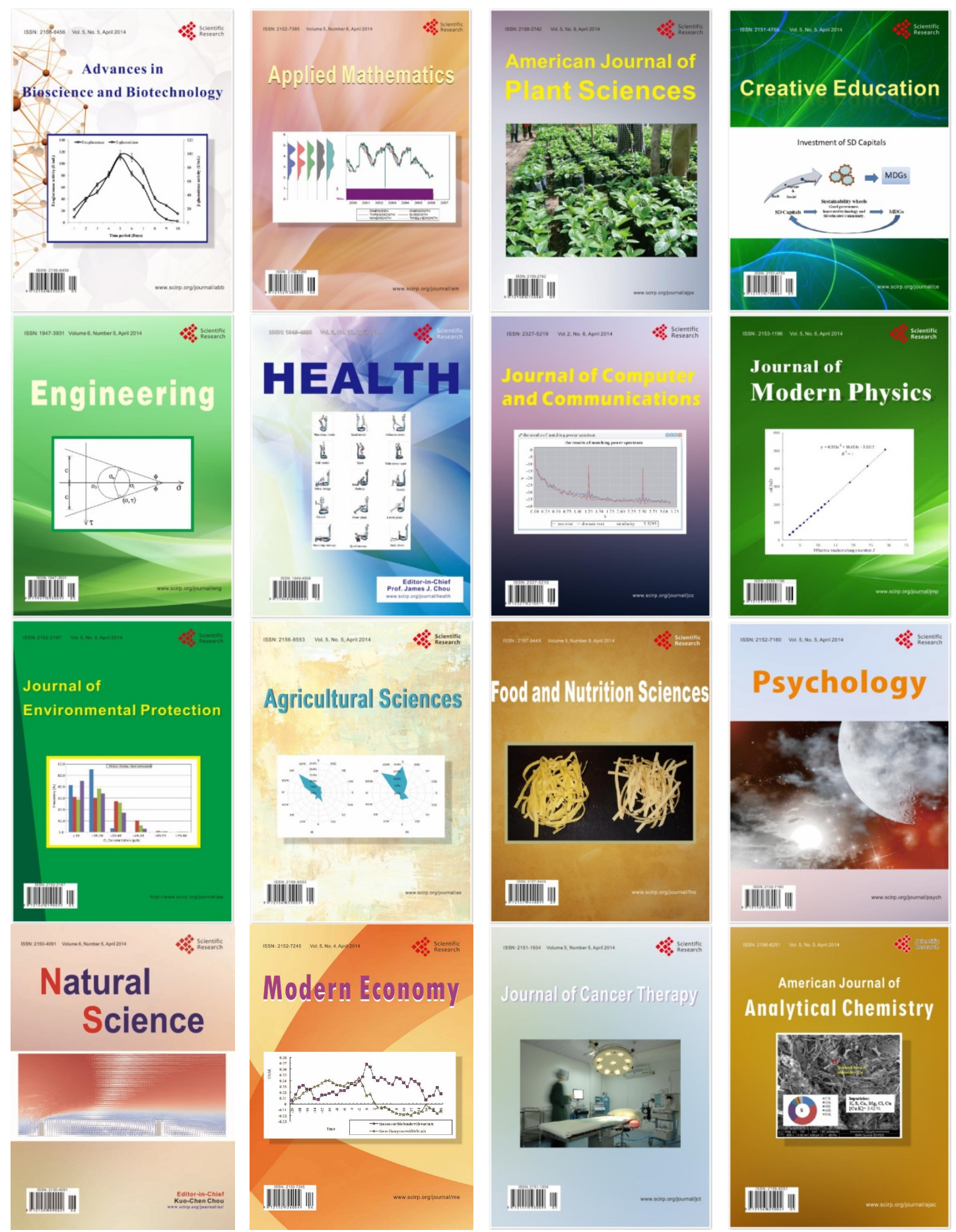